Jurnal Abdimas Kesehatan (JAK) Vol 2 No.2, Juni 2020

Doi : $10.36565 /$ jak.v2i2.80

p-ISSN: 2655-9266

e-ISSN: 2655-9218

\title{
Yoga Untuk Meringankan Tingkat Kecemasan Ibu Hamil
}

\author{
Fatihatul Hayati \\ Prodi DIII Kebidanan STIKes Baiturrahim Jambi \\ Email: fatihatulhayatianam@gmail.com
}

Submitted : 25/11/2019

Accepted: 02/12/2019

Published: 16/06/2020

\begin{abstract}
Anxiety and fear experienced by mothers especially primipara can extend the duration of labor and increase the incidence of labor by action, namely labor with cesarean section (OR 26.9 CI 95\%) and vacuum extraction (OR 4.5 CI 95\%). Felman et al also found that more than 12\% of mothers who had given birth said that they experienced anxiety during childbirth where these experiences were unpleasant times in their lives. Anxiety will be felt differently during pregnancy and third trimester anxiety is higher than the previous trimester. Pregnancy with anxiety will affect the intrauterine environment and fetal development. Anxiety has an opportunity to increase fear three times in labor and a 1.7 times chance to increase the incidence of cesarean. Mental health including pregnancy anxiety has been proven to be reduced or eliminated through physical exercise. One of the recommended physical exercises is yoga because it is low cost, easy to do and very beneficial for physical fitness and psychology. Yoga in pregnancy is more effective in reducing anxiety and depression.
\end{abstract}

Keywords: anxiety, pregnant, yoga

Kecemasan dan ketakutan yang dialami oleh ibu bersalin terutama primipara dapat memperpanjang durasi persalinan dan meningkatkan kejadian persalinan dengan tindakan, yaitu persalinan dengan seksio sesarea (OR 26,9 CI 95\%) dan vakum ekstraksi (OR 4,5 CI 95\%). Felman et al juga menemukan lebih dari $12 \%$ ibu-ibu yang pernah melahirkan mengatakan bahwa mereka mengalami cemas pada saat melahirkan dimana pengalaman tersebut merupakan saat-saat tidak menyenangkan dalam hidupnya. Kecemasan akan dirasakan berbeda selama kehamilan dan kecemasan trimester ketiga lebih tinggi dibanding trimester sebelumnya. Kehamilan dengan kecemasan akan mempengaruhi lingkungan intrauterine dan perkembangan janin. Kecemasan berpeluang meningkatkan 3 kali ketakutan dalam persalinan dan berpeluang 1,7 kali meningkatkan kejadian sectio cesarea. Kesehatan mental termasuk kecemasan kehamilan terbukti dapat dikurangi atau dihilangkan melalui latihan fisik. Salah satu latihan fisik yang direkomendasikan adalah yoga karena biaya rendah, mudah untuk dilakukan dan sangat bermanfaat untuk kebugaran fisik dan psikologi. Yoga dalam kehamilan lebih efektif dalam menurunkan kecemasan dan depresi

Kata Kunci: ibu hamil, kecemasan, yoga

\section{PENDAHULUAN}

Hasil penelitian memperlihatkan bahwa AKI lebih tinggi terjadi pada ibu yang cara persalinannya ditolong dengan tindakan dibandingkan ibu yang persalinannya berlangsung spontan. Kematian ibu tersebut disebabkan oleh perdarahan $(32 \%)$, eklampsia $(14 \%)$, partus lama (12\%), infeksi (11\%), abortus (14\%), penyakit jantung (5\%), dan lain-lain (12\%). Perdarahan ibu terjadi karena retensi plasenta, anemia berat, partus lama, dan lainnya (Mariati, dkk, 2011).

Sekitar $6 \%$ dari populasi umum mengalami gangguan cemas, generalized anxiety disorder (GAD) merupakan gangguan yang paling sering ditemui, terjadi pada $2-4 \%$ populasi (Katona, 2012). Pada ibu bersalin, Flood; et al (2001) menunjukkan masih tingginya permasalahan psikologis yang dialami ibu dalam menghadapi persalinan yaitu cemas (52\%) dan ragu akan kemampuannya mengatasi rasa nyeri (43\%). Kecemasan dan ketakutan yang dialami oleh ibu 
bersalin terutama primipara dapat memperpanjang durasi persalinan dan meningkatkan kejadian persalinan dengan tindakan, yaitu persalinan dengan seksio sesarea (OR 26,9 CI 95\%) dan vakum ekstraksi (OR 4,5 CI 95\%). Felman et al (dalam Pairman, 2011) juga menemukan lebih dari $12 \%$ ibu-ibu yang pernah melahirkan mengatakan bahwa mereka mengalami cemas pada saat melahirkan dimana pengalaman tersebut merupakan saat-saat tidak menyenangkan dalam hidupnya.

Salah satu faktor emosi atau psikologis terjadinya partus lama adalah ketakutan dan kecemasan ibu yang tidak teratasi selama melahirkan (Dolea dan Abouzahr, 2003). Old et al dalam Pairman (2011) menyatakan bahwa 65\% kejadian partus lama disebabkan karena kontraksi uterus yang tidak efisien sebagai respon terhadap kecemasan sehingga menghambat aktifitas uterus. Hal senada juga disampaikan oleh Chapman (2000), yang menyebutkan bahwa salah satu penyebab terjadinya partus lama adalah respon stres, dan ini menempati urutan paling atas di antara penyebab-penyebab yang lainnya. Kondisi ini terjadi karena ibu bersalin akan menghadapi berbagai masalah dalam adaptasinya selama proses persalinan, diantaranya rasa nyeri saat kontraksi, ketakutan akan ketidakmampuan dalam menangani masalah yang akan terjadi, ketegangan dan hiperventilasi (Brayshaw, 2007).

Kecemasan yang tidak teratasi juga merupakan prediktor terjadinya nyeri selama melahirkan yang akan mempengaruhi kesehatan ibu dan bayi. Sebaliknya nyeri selama melahirkan juga menyebabkan timbulnya kecemasan, sehingga antara stres, kecemasan, ketakutan dan nyeri Merupakan siklus yang berkesinambungan. Sementara pasien yang mengalami nyeri empat kali lebih cemas dibandingkan dengan pasien yang tidak mengalami nyeri (Thompson, et al, 2008,
Baesdo, et al, 2009).

Kecemasan akan dirasakan berbeda selama kehamilan dan kecemasan trimester ketiga lebih tinggi dibanding trimester sebelumnya. Kehamilan dengan kecemasan akan mempengaruhi lingkungan intrauterine dan perkembangan janin. Kecemasan berpeluang meningkatkan 3 kali ketakutan dalam persalinan dan berpeluang 1,7 kali meningkatkan kejadian sectio cesarean (Katona, 2012)

Kesehatan mental termasuk kecemasan kehamilan terbukti dapat dikurangi atau dihilangkan melalui latihan fisik. Salah satu latihan fisik yang direkomendasikan adalah yoga karena biaya rendah, mudah untuk dilakukan dan sangat bermanfaat untuk kebugaran fisik dan psikologi. Yoga dalam kehamilan lebih efektif dalam menurunkan kecemasan dan depresi (Hall, 2016). Yoga antenatal adalah sebuah ilmu yang menjelaskan kaitan antara fisik, mental, dan spiritual manusia untuk mencapai kesehatan yang menyeluruh. Melakukan latihan yoga pada saat hamil, akan mempersiapkan tubuh maupun pikiran untuk siap dan tegar menghadapi masa persalinan.

Pada saat melakukan gerakan yoga, hipotalamus akan mempengaruhi sistem saraf otonom yaitu menurunkan aktivitas saraf simpatis dan meningkatkan aktivitas saraf parasimpatis. Yoga akan menghambat peningkatan saraf simpatis sehingga hormon penyebab disregulasi tubuh dapat dikurangi jumlahnya. Sistem saraf parasimpatis memberi sinyal untuk mempengaruhi pengeluaran katekolamin. Akibatnya, terjadi penurunan detak jantung, irama nafas, tekanan darah, ketegangan otot, tingkat metabolisme, dan produksi hormon penyebab kecemasan atau stres. Yoga mempengaruhi pula hipotalamus untuk menekan sekresi $\mathrm{CRH}$ yang akan mempengaruhi kelenjar hipofisis lobus anterior untuk menekan 
pengeluaran hormon ACTH sehingga produksi hormon adrenal dan kortisol menurun serta memerintahkan kelenjar hipofisis lobus anterior mengeluarkan hormon endorphin (Streeter, 2012).

Berdasarkan uraian latar belakang diatas diperlukan pemberdayaan ibu hamil dalam beradaptasi dengan perubahan fisiologis dan psikologisnya terutama upaya mengatasi kecemasan selama kehamilan melalui kegiatan yoga kehamilan, sehingga ibu hamil dapat menjalani kehamilan dan persalinan dengan aman dan nyaman.

\section{TARGET DAN LUARAN}

1. Target

Luaran yang diharapkan dari kegiatan yoga untuk meringkankan kecemasan pada masa kehamilan antara lain ibu dapat mengendalikan pikiran, emosi dan perubahan psikologis yang dialami sehingga dapat beradaptasi dengan perubahan fisiologisnya. Ibu hamil yang sehat secara fisik dan mental akan melahirkan bayi yang sehat dan dapat merawat bayinya dengan baik saat setelah kelahiran nanti.

2. Luaran

Adapun luaran kegiatan pengabdian ini adalah ada peningkatan pengetahuan dan keterampilan ibu bayi/ Baduta tentang:

a. Pengenalan Yoga Prenatal

b. Tahapan Yoga Prenatal

c. Manfaat Yoga Prenatal

d. Praktik yoga prenatal dibimbing oleh instruktur yoga tersertifikasi

Hasil kegiatan edukasi yoga untuk meringkankan kecemasan pada masa kehamilan ini juga akan dipublikasikan dalam bentuk jurnal ilmiah nasional sehingga dapat diakses oleh masyarakat.

\section{METODE PELAKSANAAN}

Kegiatan pengabdian kepada masyarakat tentang Yoga untuk meringankan tingkat kecemasan ibu hamil ini dilaksanakan pada bulan Maret -April 2019 di Wilayah kerja Puskesmas Putri Ayu
Kota Jambi.

Tahapan kegiatan pengabdian kepada masyarakat meliputi :

Persiapan

1. Sosialisasi : Pertemuan dengan Kepala Puskesmas dan Bidan Koordinator Puskesmas Putri Ayu Kota Jambi, kemudian mengurus administrasi dan menyepakati jadwal pelaksanaan pengabdian masyarakat.

2. Mengidentifikasi masalah

3. Perumusan solusi : memberikan pendidikan kesehatan dan bimbingan latihan yoga kehamilan kepada ibu hamil terimester II dan trimester III.

Pelaksanaan : Melakukan pretest (menggali pemahaman ibu hamil tentang Yoga kehamilan. Memberikan pendidikan kesehatan tentang Yoga Kehamilan serta Membimbing ibu hamil melakukan Yoga Kehamilan.

\section{HASIL DAN PEMBAHASAN}

Kegiatan ini bertujuan agar ibu memahami manfaat yoga kehamilan dalam meringankan kecemasan selama kehamilan dan menghadapi persalinan dan dapat melakukan yoga secara mandiri di rumah.

Kegiatan pengabdian kepada masyarakat ini dilaksanakan bersamaan dengan kegiatan Praktik Klinik Komprehensif mahasiswa D III Kebidanan Stikes Baiturrahim. Dalam kegiatan ini dilakukan pemberian pendidikan kesehatan berkaitan dengan perubahan psikologis ibu hamil, penyebab kecemasan ibu hamil, cara mengatasi kecemasan ibu hamil serta peranan yoga dalam menurunkan kecemasan ibu hamil. Pengabdian kepada masyarakat ini melibatkan 2 orang mahasiswa yang pada saat bersamaan juga sedang melaksanakan Praktik Klinik Komprehensif di poli KIA Puskesmas Putri Ayu.

Menurut Indiarti (2009) dalam Gustina 2019, senam hamil yoga memiliki lima cara yaitu latihan fisik yoga, pernafasan (pranayama), positions (mudra), meditasi 
dan deep relaksasi yang dapat digunakan untuk mendapatkan manfaat selama kehamilan yang dapat membantu kelancaran dalam kehamilan dan kelahiran anak secara alami dan sehat.

Setelah dilakukan pendidikan kesehatan, ibu hamil dibimbing untuk melakukan yoga oleh instruktur yoga prenatal yang tersertifikasi. Diharapkan ibu hamil dapat mengulang kembali gerakan yoga di rumah sesuai dengan kebutuhannya, sehingga ibu dapat mengatasi kecemasan yang dialaminya.

Setelah dilakukan pendidikan kesehatan tentang perubahan psikologis ibu hamil dan yoga pada kehamilan, dilakukan evaluasi secara lisan, didapatkan hasil :

a) Ibu mengerti perubahan psikologis pada kehamilan

b) Ibu memahami penyebab kecemasan pada kehamilan

c) Ibu memahami cara mengatasi kecemasan selama kehamilan

d) Ibu mengetahui peranan yoga dalam mengatasi kecemasan pada kehamilan

e) Ibu mengetahui langkah-langkah yoga untuk menenangkan pikiran sehingga dapat mengatasi kecemasan pada kehamilan

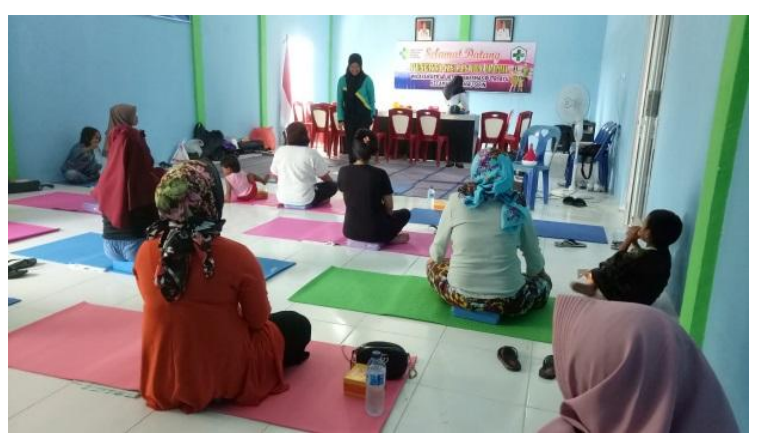

Gambar 1. Pemberian Materi tentang Yoga Kehamilan

Hari kedua tim melanjutkan dengan mengulang gerakan-gerakan yoga kehamilan dan mengevaluasi kemampuan ibu untuk mengikuti setiap gerakan.

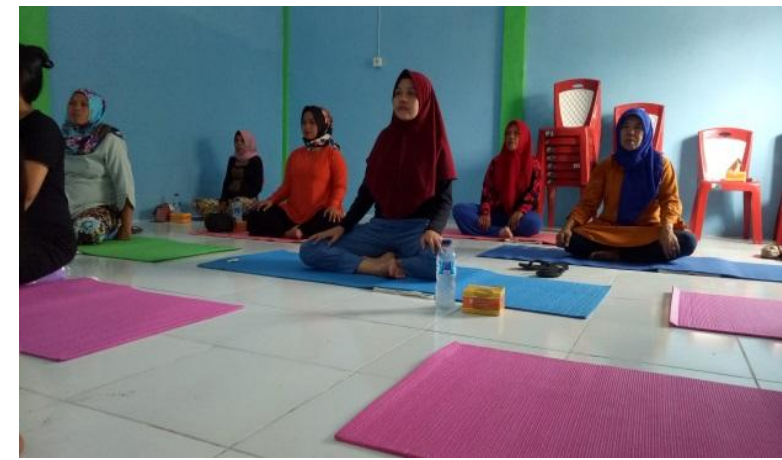

Gambar 2. Pelaksanaan Yoga Kehamilan

\section{KESIMPULAN DAN SARAN \\ 1. Kesimpulan}

Setelah diberikan pendidikan kesehatan dan bimbingan yoga dalam kehamilan didapatkan peningkatan pengetahuan ibu hamil tentang perubahan psikologis ibu hamil dan peranan yoga dalam mengatasi kecemasan pada kehamilan sehingga diharapkan ibu hamil dapat mengatasi kecemasan agar dapat menjalani kehamilan dengan sehat, aman dan nyaman serta melahirkan bayi yang sehat baik fisik maupun mental.

\section{Saran}

Kecemasan merupakan perubahan psikologis yang normal muncul saat kehamilan, namun jika tidak diatasi dapat berakibat kurang baik terhadap kesehatan ibu maupun janin. Untuk itu perlu peran aktif tenaga kesehatan untuk dapat memfasilitasi ibu hamil dalam mengatasi kecemasan yang dirasakannya dan memberikan edukasi agar ibu dapat mengatasinya secara mandiri.

\section{UCAPAN TERIMAKASIH}

Ucapan terimakasih Kami sampaikan kepada Sekolah Tinggi Ilmu Kesehatan Baiturrahim yang telah menfasilitasi kegiatan ini, kepada Bapak Kepala Puskesmas Putri Ayu Kota Jambi beserta jajarannya yang banyak membantu kegiatan ini, ibu hamil yang berkunjung di Puskesmas Putri Ayu yang bersedia menjadi peserta kegiatan pengabdian masyarakat ini. 
DAFTAR PUSTAKA

Dolea, C., Abouzahr, C. 2003. Global Burden of Obstructed of Labour in the Year 2000, WHO

Gustina, 2019, Pelaksanaan Senam Hamil Yoga Untuk Kesiapan Ibu Hamil Trimester Iii Menghadapi Persalinan Di Puskesmas Putri Ayu Tahun 2019, Jurnal Abdimas Kesehatan (Jak) Vol 1,No.2, Juni 2019, Http://Jak.Stikba.Ac.Id/Index.Php/Jak/Art icle/View/35

Hall, H. G., Beattie, J., Lau, R., East, C. \& Anne, M. (2016) Mindfulness and perinatal mental health: a systematic review. Women Birth, 29 (1): 62-71

Katona, Cornelius, Claudia Cooper, Mary Robertson. 2012. At a Glance Psikiatri Edisi Keempat. Jakarta: EGC

Mariati, Ulvi, Agus, Z, Sulin, D, Masrul, Amri Z. Dkk. 2011. Studi Kematian Ibu dan Kematian Bayi di Provinsi Sumatera Barat. Artikel Penelitian. Jurnal Kesehatan Masyarakat Nasional Vol. 5 no. 6

Pairman, Sally. 2011. Midwifery: Preparation for Practice 2nd ed. Australia: Elsevier

Streeter, C. C., Gerbarg, P. L., Saper, R. B., Ciraulo, D. A. \& Brown, R. P. (2012) Effects of yoga on the autonomic nervous system, gammaaminobutyricacid, and allostasis in epilepsy, depression, and post-traumatic stress disorder. Med Hypotheses, 78 (5): 571-9. 